\title{
PREKOMEJNA ZEMLJIŠKOPOSESTNA POMEŠANOST IN ZAPOSLOVANJE - PRIMER OBMEJNIH OBČIN SV SLOVENIJE S HRVAŠKO
}

\author{
Borut Belec*
}

Izvleček

UDK 911.3:33(497.12-18-04)

$Z$ analizo zemljiškoposestnih in zaposlitvenih značilnosti so opredeljeni nekateri elementi čezmejne regionalne povezanosti prebivalstva petih občin severovzhodne Slovenije ob državni meji s Hrvaško. Stopnja dosedanje povezanosti je bila zaradi odprtosti nekdanje medrepubliške meje zelo visoka, zato bo prepustnost nove meje $v$ prihodnje pomemben dejavnik družbenoekonomskega razvoja tamkajšnjih manj razvitih območij.

Ključne besede: Družbena geografija, obmejna območja, mejni tip, Slovenija

Abstract

UDC 911.3:33(497.12-18-04)

THE LANDOWNERSHIP AND EMPLOYMENT STRUCTURE ALONG THE CROATO-SLOVENE BORDER

On the basis of the analysis of the characteristics of landed property and employment some elements of across the border regional links of five communities in the northeastern part of Slovenia along the State boundary with Croatia have been defined. The level of such connections up till now was, due to the opennes of the former border between the republics, very high. Therefore, the future permeability of the new border will become one of the key elements in the social-economic development of those under-developed regions.

Key words: Social geography, border regions, type of border, Slovenia

\section{UVOD}

$\mathrm{Z}$ osamosvojitvijo Slovenije in nastankom državne meje med Republiko Slovenijo in Republiko Hrvaško v letu 1991 so se odprli mnogi obmejni problemi, saj je nova funkcija meje omejila ali pretrgala tradicionalne gospodarske tokove tamkajšnjega prebivalstva.

Slovenska geografija je v okviru regionalnih raziskav že doslej, zlasti pa od sedemdesetih let dalje, proučevala tudi obmejno problematiko mejnih območij ob državnih mejah nekdanje Jugoslavije z Avstrijo, Italijo in Madžarsko s posebnim poudarkom na problemih etničnih manjšin. Pri tem je najpogosteje uporabljala socialnogeografski prostop, ki postavlja $\mathrm{v}$ ospredje kompleksnost obmejnega prostora v smislu kulturne, socialne in ekonomske integriranosti obmejnih regij (prim. Klemenčič 1974, 1976, 1987, 1989, Olas 1976, Bufon 1992). Socialnogeografskim aspektom obmejnih območij je bila namenjena tudi 6. številka Geographice Slovenice v letu 1978. Političnogeografske in družbenoekonomske spremembe posameznih mejnih sektorjev, ki že na primeru SV Slovenije kažejo velike naravne in družbene razlike (Belec 1978, 1992).

* Dr., red. prof., Oddelek za geografijo, Pedagoška fakulteta, Univerza v Mariboru, Koroška c. 160, 62000 Maribor, SLO 


\section{ZNAČILNOSTI MEJNEGA REŽIMA}

Severovzhodna Slovenija ima značaj nizkega ravninskega in gričevnatega sveta, ki ga prečkata reki Mura in Drava. Meja poteka zato najčešče po obeh rekah in dolinah njunih pritokov ter po reki Sotli, pritoku Save. Razvodna slemena predstavljajo mejo le v Medmurskih goricah ter Vzhodnih Halozah. Na obravnavanem sektorju slovensko-hrvaške meje je 7 mednarodnih, 3 meddržavni in 2 obmejna prehoda.

Iz nekdanje medrepubliške meje $\mathrm{v}$ okviru Jugoslavije, ki jo je kot posledica enotnega družbenopolitičnega sistema razpadle države označevala dokaj visoka stopnja socialne in ekonomske integracije prebivalstva, se je oblikovala meja, ki glede na mejne modele še najbolj ustreza t.i. mostovnemu tipu. Zanj je značilno, da je relativno zaprt, prehodi so redki, vendar obstaja kontrolirana izmenjava blaga, oseb in informacij. Do bolj ali manj intenzivne integracije ali spajanja dveh družbenoekonomskih sistemov s tendenco nadnacionalnega razvoja pri njem ne prihaja (Schultes - Becker 1990). Podrobnejšo tipološko proučitev nove meje in njeno uvrstitev v modelno strukturo bo omogočila šele normalizacija razmer na ozemlju nekdanje Jugoslavije. Zato je v primerjavi z drugimi evropskimi mejami glede na stopnjo prepustnosti sedaj še ni mogoče določneje opredeliti. Meddržavni sporazumi o dvolastništvu, maloobmejnem prometu in zaposlovanju bi gotovo morali omogočiti odprto mejo s čim bolj neoviranim povezovanjem obmejnega prebivalstva in razvoj v t.i. tečajni tip meje. Slednje bi tudi omogočilo uspešno načrtovanje gospodarstva tukajšnjih manj razvitih in demografsko ogroženih obmejnih regij. Pri tem bodo gotovo imeli pomembno inovacijsko vlogo centralni kraji z oskrbno, zaposlitveno ali še kakšno drugo funkcijo za obmejno prebivalstvo (Pak, 1987).

\section{NEKAJ DEJAVNIKOV DIFERENCIRANOSTI MEJNIH OBMOČIJ}

Naravnogeografske razmere v SV Sloveniji so kljub enotnemu subpanonskemu značaju dokaj pestre. Ugodne reliefne, klimatske in pedološke razmere so omogočile razvoj različnih kmetijskih panog, v ravninskem svetu zlasti poljedelstva in živinoreje, $v$ gričevnatem vinogradništva in sadjarstva. Nekatera območja še $\mathrm{v}$ znatni meri prekriva gozd.

Razvoj neagrarnih dejavnosti v slovenskih obmejnih središčih je po 2. svetovni vojni omogočil zaposlitev hrvaškega prebivalstva v Lendavi, Ljutomeru, Rogatcu, Rogaški Slatini, Podčetrtku in drugod. Slovenci so se na Hrvaškem zaposlili le izjemoma, tako npr. iz območja Rogatca v sosednji Straži. Dnevni migranti prihajajo v pomurske in podravske obmejne občine iz Hrvaškega Medmurja in z Varaždinske ravnine, v občino Šmarje pa iz Hrvaškega Zagorja.

Poselitev mejnih območij je razmeroma gosta, zlasti v ravninskem svetu. Ker pa razvoj neagrarnih dejavnosti v obmejnih centralnih krajih ni zadoščal za zaposlitev odvečne delovne sile, se je prebivalstvo po 2. svetovni vojni močno izseljevalo. Depopulacijo sta pospeševali 
šibka zemljiškoposestna struktura in ponekod visoka stopnja podružbljenosti zemlje, npr. v Jeruzalemskih goricah in Halozah. Zemljišča so zato pogosto prehajala v roke hrvaškega prebivalstva, ki se je tudi priseljevalo in svojo posest na Hrvaškem deloma obdržalo. Pomembno vlogo so imeli pri tem mešani zakoni.

Po drugi strani so na Hrvaškem kupovali vinograde slovenski kmetje, npr. z Murskega polja, ki so po 2. svetovni vojni z zakonom o viničarskih razmerjih tovrstno posest izgubili. Sicer pa je zemljiško pomešanost pospeševala želja nižinskega prebivalstva po vinogradniški zemlji tudi drugod, npr. z Dolinskega in Hrvaškega Medmurja v Lendavskih in Medmurskih goricah. Manj potrebe po takšnem dopolnjevanju kmetijske produkcije kažejo po naravi manj homogena območja, npr. Posotelje.

K zemljiški pomešanosti so prispevale tudi prestavitve vodnih tokov, zlasti mejne Mure in Drave, kjer potekajo meje katastrskih občin mnogokje po nekdanjem rečnem toku, oziroma mrtvih rokavih.

Nemalo je na zemljiškoposestno pomešanost in zaposlovanje vplival zgodovinski razvoj. Značilen primer je Medmurje, ki je z izjemo obdobja 1848-1864, ko je bilo pridruženo Hrvaški, do l. svetovne vojne kot del zalske županije pripadalo ogrskemu delu monarhije. Tako po 1. kot po 2. svetovni vojni se je na tem območju meja med Slovenijo in Hrvaško spreminjala. Ljutomer je pritegoval delovno silo ne le iz Slovenskega, temveč tudi Hrvaškega Medmurja, npr. iz območja Štrigove (Belec 1968, 1992). V Lendavske gorice in na Dolinsko pa je po zemljiški posest močno poseglo prebivalstvo iz ravninskega dela Hrvaškega Medmurja (Bračič 1988).

\section{PREKOMEJNA ZEMLJIŠKA POSEST IN ZAPOSLITEV}

V analizi so zajete občine Lendava, Ljutomer, Ormož, Ptuj in Šmarje pri Jelšah (Podatki geodetskih in davčnih uprav ter podjetij, 1991). V številu lastnikov so v občini Lendava in naseljih Dolina ter Hotiza upoštevani tudi solastniki (*). Glavne značilnosti zemljiškega dvolastništva so razvidne iz tabel 1 in 2.

Razširjenost zemljiške posesti lastnikov iz Hrvaške v obmejnih občinah severovzhodne Slovenije je razvidna tudi iz kartograma.

Neglede, da so v številu lastnikov zajeti solastniki, je hrvaška posest največja v občini Lendava, kjer ima 2963 lastnikov 305 ha zemlje ali $3.14 \%$ občinske površine. V k.o. Petišovci znaša delež njihove posesti $12.1 \%$, v k.o. Pince celo $31.7 \%$ površine. Na obe k.o. odpade kar 2146 ali $72 \%$ hrvaških lastnikov s 703 ha ali $87 \%$ njihove posesti v občini Lendava. 
Tab. 1: Zemljiška posest lastnikov iz Hrvaške v obmejnih občinah severovzhodne Slovenije leta 1992

Grundbesitz der Eigentuemer aus Kroatien in den Grenzgemeinden Nordostsloweniens im Jahr 1992

Občina

Zemljiške kategorije $\mathrm{v}$ ha

$\%$ na lst.

Št. 1st. Sk. Nj. Sa. Vi. Tr. Pa. Go. Ne. v ha ob.p

\begin{tabular}{lrrrrrrrrrrr} 
Lendava* & 2963 & 805 & 360 & 5 & 104 & 228 & 46 & 18 & 43 & 3.14 & 0.27 \\
Ljutomer & 341 & 94 & 41 & 6 & 1 & 15 & 0 & 25 & 6 & 0.52 & 0.27 \\
Ormož & 609 & 334 & 97 & 8 & 19 & 45 & 6 & 158 & 1 & 1.57 & 0.55 \\
Ptuj & 710 & 326 & 24 & 8 & 10 & 107 & 53 & 117 & 7 & 0.50 & 0.46 \\
Šmarje J. & 337 & 138 & 17 & 1 & 5 & 50 & 6 & 55 & 4 & 0.34 & 0.41 \\
Skupaj & 4960 & 1967 & 539 & 28 & 139 & 445 & 111 & 374 & 61 & 1.07 & 0.34 \\
$\quad \%$ & & & 100 & 32 & 2 & 8 & 26 & 7 & 22 & 3 & \\
\hline
\end{tabular}

Tab. 2: Število katastrskih občin $\mathrm{z}$ deležem površin zemljiških lastnikov iz Hrvaške v obmejnih občinah severovzhodne Slovenije leta 1992

Die Zahl der Katastralgemeinden mit den Bodenanteil der Eigentuemer aus Kroatien in den Grenzgemeinden Nordostsloweniens im Jahr 1992

Delež površin Število k.o. v občinah

pok.o.v\% Lendava Ljutomer Ormož Ptuj Šmarje Skupaj \%

\begin{tabular}{lrrrrrrr}
\hline Do 0.50 & 13 & 23 & 22 & 24 & 14 & 96 & 51.6 \\
$0.51-1.00$ & 2 & 4 & 6 & 6 & 5 & 23 & 12.4 \\
$1.01-2.00$ & 4 & 1 & 6 & 6 & 5 & 22 & 11.8 \\
$2.01-5.00$ & 2 & 1 & 6 & 10 & 6 & 25 & 13.4 \\
$5.01-10.00$ & 0 & 4 & 2 & 10 & 0 & 16 & 8.6 \\
Nad 10.01 & 2 & 0 & 1 & 1 & 0 & 4 & 2.2 \\
Skupaj & 23 & 33 & 43 & 57 & 30 & 186 & 100.0
\end{tabular}

Zemljiška posest lastnikov iz občine Lendava v Hrvaškem Medmurju je prav tako izredno močna. Vseh lastnikov je 296, največ iz Hotize, Velike Polane, Lendave, Dolnje in Gornje Bistrice, Kota , Petišovec in Gaberja. Nekaj zemljišč na Hrvaškem ima tudi družbeni sektor. $\mathrm{O}$ tej posesti manjkajo podatki.

Kot primer prekomejne zemljiškoposestne pomešanosti lahko služita k.o. Dolina in Hotiza. Dolina leži v Lendavskih goricah in je tipično vinogradniško, Hotiza mejno ravninsko naselje ob Muri. Razlikujeta se tudi po značaju prekomejne pomešanosti posesti. Medtem ko je v 
Prekomejna zemljiška posestna ...

k.o. Dolina* 405 hrvaških lastnikov, ki posedujejo 31.2 ha ali $10 \%$ vse zemlje, od tega 21 ha ali $32.8 \%$ vinogradov, ima v Hotizi* le 7 hrvaških lastnikov, skupaj 0.6 ha. Stanje je obratno v pogledu slovenske posesti na Hrvaškem. Iz Doline sta takšna lastnika le 2, iz Hotize pa jih je kar 225. Posest slednjih leži neposredno ob naselju pod ježo nekdanjih murskih meandrov, po katerih poteka državna meja.

V k.o. Dolina* je 312 ha ali $45.7 \%$ zasebnih zemljišč, od tega jih je $63 \%$ v posesti lastnikov iz Doline, $25 \%$ v posesti lastnikov iz sosednjih in drugih k.o. ter $10 \%$ iz Hrvaške. Slednji imajo kar 21 ha ali $32.6 \%$ vseh vinogradov. Od 1027 lastnikov jih je iz Hrvaške celo 405. Posebno vinogradniška posest je skrajno razdrobljena, saj odpade na enega lastnika 6.26 a. Lastniki zemljišč iz Hrvaške so pretežno iz medmurskih naselij Križovec, Miklavec, Peklenica, G. Kraljevec, Podturen, Mursko Središče, Ferketinec in Vratišinec.

V tej občini ugotavljamo tudi najmočnejši zaposlitveni tok iz Hrvaške, saj je zaposlenih 689 oseb, največ v podjetjih Nafta Lendava, Gradbenik, Elektromaterial, Gidos in Integral. Pri Gradbeniku predstavlja hrvaška delovna sila celo $50 \%$ vseh zaposlenih.

V občini Ljutomer ima 341 lastnikov iz Hrvaške 94 ha zemlje. Najmočnejša je njihova posest v Slovenskem Medmurju, in to v k.o. Veščica, Razkrižje, Gibina in Globoka. V navedenih k.o. je 262 ali $76 \%$ vseh hrvaških lastnikov s 60 ha ali $63 \%$ njihove posesti v občini. Kar 125 ali 37 \% jih je iz k.o. Banfi, 26 iz Zagreba, 21 iz k.o. Robadje itd.

Lastniki iz občine Ljutomer imajo na Hrvaškem 275 ha zemlje, pogosto vinograde, največ v obmejnih k.o. Štrigova in Robadje.

Kot značilen primer zemljiškoposestne pomešanosti si oglejmo mejno k.o. Gibina. Od skupne površine 154.5 ha odpade 18.3 ha na nerodovitna družbena zemljišča, sicer pa prevladujejo njive s $53.5 \%$. Tudi hrvaška posest je največ omejena nanje (tab.3).

Tab. 3: Zemljiška posest v k.o. Gibina leta 1992 glede na prebivališče lastnikov (v ha) Der Grundbesitz in Katastralgemeinde Gibina mit Bezug auf den Wohnort der Besitzer im Jahr 1992 (in ha)

\begin{tabular}{lrrrrrr}
\hline Zemlj.kat. & Gibina & Sos.k.o. & Druge k.o. & Hrvaška & Ostali & Skupaj \\
\hline Njiva & 58.0 & 10.4 & 7.5 & 6.4 & 0.3 & 82.6 \\
Sadovnjak & 16.6 & 0.5 & 0.3 & 0.5 & 0.0 & 17.9 \\
Vinograd & 0.1 & - & - & - & - & 0.1 \\
Travnik & 10.4 & 0.9 & 1.8 & 1.0 & - & 14.1 \\
Pašnik & 1.8 & 0.0 & 0.0 & 0.0 & 0.0 & 1.8 \\
Gozd & 9.0 & 0.9 & 0.7 & 1.2 & 0.2 & 12.0 \\
Nerod.z. & 6.7 & 0.3 & 0.4 & 0.2 & 0.1 & 7.7 \\
Skupaj & 102.6 & 13.0 & 0.7 & 9.3 & 0.6 & 136.2
\end{tabular}


Slika 1: Delež zemljiških lastnikov iz Hrvaške v obmejnih območjih SV Slovenije leta 1992 po katastrskih občinah

Bodenanteile der Eigentümer aus Kroatien in Katastralgemeinden der Grenzgemeinden Nordostsloweniens im Jahr 1992

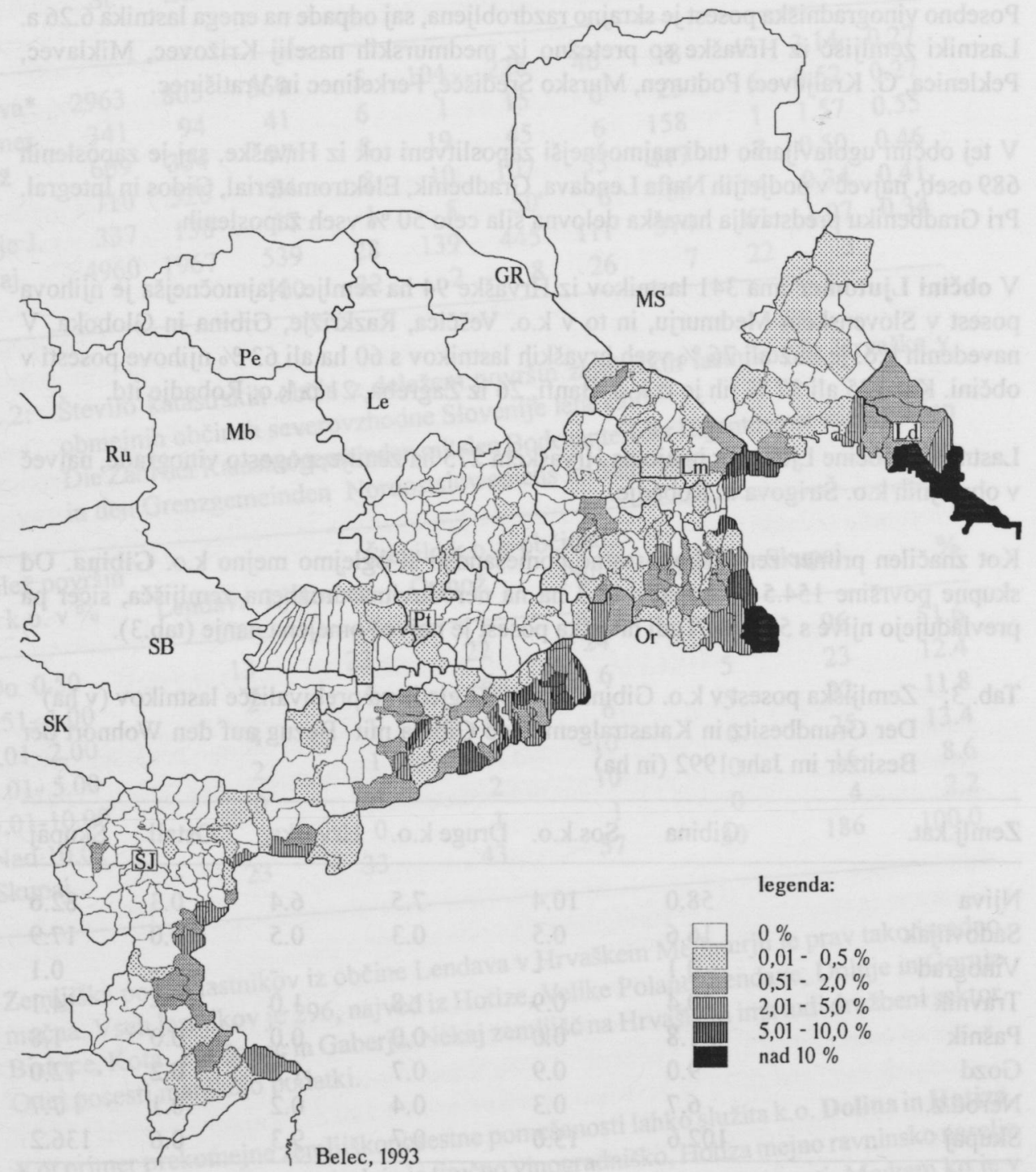


Lastnikov iz Hrvaške v k.o. Gibina je 55 ali $17.9 \%$. Tudi v tem območju je razdrobljenost posest izredno močna, saj je lastnikov z manj kot 0.5 ha zemlje kar 71 \% (tab.4).

Tab. 4: Lastniki zemljišč glede na prebivališče in velikost posesti v k.o. Gibina leta 1992 Die Grundbesitzer mit Bezug auf den Wohnort und Groesse des Besitzes in Katastralgemeinde Gibina im Jahr 1992

\begin{tabular}{lrrrrrr}
\hline ha & Gibina & Sos. k.o. & Druge k.o. & Hrvaška & Ostali & Skupaj \\
\hline Do 0.5 & 84 & 30 & 49 & 52 & 4 & 219 \\
$0.5-1$ & 33 & 5 & 5 & 3 & - & 46 \\
$1-2$ & 29 & - & 1 & - & - & 30 \\
$2-3$ & 7 & 2 & - & - & - & 9 \\
$3-5$ & 3 & - & - & - & - & 3 \\
Skupaj & 156 & 37 & 55 & 55 & 4 & 307 \\
\hline
\end{tabular}

Posest Gibinčanov na Hrvaškem znatno presega posest lastnikov iz Hrvaške, saj ima 61 posestnikov v občini Čakovec 50.6 ha zemlje (tab.5)

Tab. 5: Zemljiška posest lastnikov iz k.o. Gibina na Hrvaškem leta 1992 v ha (občina Čakovec)

Der Grundbesitz der Besitzer aus Katastralgemeinde Gibina in Kroatien im Jahr 1992 (Gemeinde Čakovec, in ha)

\begin{tabular}{lrrrr}
\hline Zemlj. kat. & Sosednje k.o. & Druge k.o. & Skupaj & $\%$ \\
\hline Njiva & 29.0 & 0.2 & 29.2 & 57.9 \\
Sadovnjak & 2.3 & - & 2.3 & 4.5 \\
Vinograd & 5.0 & 0.3 & 5.3 & 10.5 \\
Travnik & 3.2 & 2.0 & 5.2 & 10.2 \\
Pašnik & - & - & - & - \\
Gozd & 8.0 & 0.6 & 8.6 & 16.9 \\
Nerod.z. & - & - & - & - \\
Skupaj & 47.5 & 3.1 & 50.6 & 100.0
\end{tabular}

Njihova zemljišča leže pretežno v sosednjih mejnih k.o. občine Čakovec.

V občino Ljutomer prihaja dnevno na delo iz Hrvaške 332 oseb. Največ jih dela v podjetjih Mura, Imgrad, PGP in Tehnostroj. 
V občini Ormož ima 609 lastnikov iz Hrvaške 334 ha zemlje. Najštevilnejši so v k.o. Središče, kjer ima 241 lastnikov 139 ha zemlje ali $12.1 \%$ površine k.o. Sledijo k.o. Trgovišče, Vodranci, Gomila in Obrež. V naštetih k.o. je 349 ali 72 \% vseh hrvaških lastnikov z 201 ha ali 60 \% zemlje v občini. Največ so iz Trnovca, Belice, Gornjega Hrašćana, Čakovca, Zagreba, Macinca, Lovrečana, Nedelišća in Varaždina.

Zemljiških lastnikov iz občine Ormož je na Hrvaškem 172, največ v k.o. Družbinec, Sv. Urban, Stanetinec, Robadje in Križovljan.

V ormoških podjetjih je zaposlenih 126 hrvaških delavcev, tako v Merkator-Ogradu, Tovarni sladkorja, Optiplastu, Plastdispenserju, deloma tudi v Drogi- Gosad v Središču ob Dravi.

V občini Ptuj ima 710 lastnikov iz Hrvaške 326 ha zemlje. Delež njihove posesti je posebno visok v k.o. Drenovec (26.6 \%), v k.o. Mali Okič, Goričak, Pestike, Zakl, Meje, Korenjak, Velika Varnica in Cirkulane pa se giblje med 6 in $10 \%$. Največ zemlje (38 ha) imajo v k.o. Velika Varnica, od tega 21 ha gozda. V navedenih k.o. je 298 ali 42 \% vseh hrvaških lastnikov s 153 ha ali $47 \%$ zemlje v občini. Najpogostejši so iz naselij Dubrava, Nadkrižovljan, Gornja Voća, Donja in Gornja Višnjica, Babinec in Trakošćan.

V občini Šmarje pri Jelšah je 337 lastnikov iz Hrvaške s 138 ha zemlje. Posebno številni so v k.o. Podčetrtek (42), Kunšperk (42), Vonarje (37) in Rjavica (33). V teh k.o. je 154 ali 45 $\%$ vseh hrvaških lastnikov s 63 ha ali $45 \%$ zemlje v občini.

Iz občine ima na Hrvaškem 113 lastnikov nad 90 ha zemlje.

V tej občini je zaposlenega največ hrvaškega prebivalstva. Dnevno prihaja na delo 1308 oseb, kar predstavlja $13.6 \%$ vseh zaposlenih. V Rogaški Slatini dela preko 900 oseb, predvsem v Steklarni, Korsu in Zdravilišču.

\section{LITERATURA IN VIRI}

Belec, B., 1968, Ljutomersko-ormoške gorice. Agrarna geografija. Maribor.

Belec, B., 1978, Prostorska diferenciranost obmejnih območij severovzhodne Slovenije v luči demografskih razmer. Geographica Slovenica 6. Ljubljana, str. 35-44.

Belec, B., 1992, Nekaj značilnosti zemljiškoposestne in zaposlitvene povezanosti med republikama Slovenijo in Hrvatsko v obmejnih območjih Severovzhodne Slovenije. Geographica Slovenica 23. Ljubljana, str. 363-366.

Berenyi, J., 1993, Sozialgeographische Aspekte in der Forschung der Grenzgebiete. Arbeitsmaterialien zur Raumordnung und Raumplanung. Heft 83. Bayreuth, str. 43-48. 
Bračič, V., 1988, Lendavske gorice. Geografska monografija. Geografski zbornik XXVIII. Ljubljana, str. 35,36,55.

Bufon, M., 1992, Geografija obmejnosti: da ali ne ? Geographica Slovenica 23. Ljubljana, str. $346,354,356$.

Erdoesi, F., 1993, Strukturen und Entwicklungsprobleme in den Grenzgebieten Ungarns. Arbeitsmaterialien zur Raumordnung und Raumplanung. Heft 83. Bayreuth, str. $17-41$.

Geographica Slovenica 6, 1978, Socialnogeografski aspekti obmejnih območij Slovenije. Ljubljana.

Klemenčič, V., 1974, Odprta meja med Jugoslavijo in Italijo in vloga manjšin. Teorija in praksa, 9-10.

Klemenčič, V., 1987, Državna meja na območju SR Slovenije in obmejna območja kot nov geografski fenomen. Razprave in gradivo, 20, str. 16.

Klemenčič, V., 1989, The Function of Borders and the Development of Border Regions within Yugoslavia. Geographica Iugoslavica X. Zagreb, str. 323-337.

Klemenčič, V., 1993, National Minorities as an Element of the Demographic and Spatial Structure of the Alpine-Adriatic-Pannonian Region. GeoJournal 30.3.

Klemenčič, V. - Genorio R., 1990, The New State of Slovenia and Its Function within the Frame of Europe. GeoJournal 30.3.

Maier, J., 1990, Bedeutung und Auswirkungen von Grenzen zur DDR und ČSFR, oder: Wie veraendern offene Grenzen einen Raum? Arbeitsmaterialien zur Raumordnung und Raumplanung. Heft 26. Bayreuth, str. 1-20.

Maier, J. - Birk F., 1993, Wirtschaftsstrukturen im Umbruch - Auswirkungen der Grenzoeffnung auf den Einzelhandel und das Konsumverhalten in Marktredewitz (Bayern und Cheb) Boehmen. Regional Problems in East-Central Europa after the Political Changes.Pecs,str. 140.

Olas, L., 1976, Dvolastništvo - dejavnik v razvoju Prekmurja kot obmejne regije. Geografski vestnik XLVIII.Ljubljana,str.151-155.

Pak, M., 1987, Meja kot faktor razvoja obmejnih območij. Zbornik radova naučnog simpozijuma. Vranje, str. 13-22.

Podatki geodetskih in davčnih uprav občin Lendava, Ljutomer, Ormož, Ptuj in Šmarje pri Jelšah ter podjetij, 1992. Obdelava: mag. Uroš Horvat, Silvija Prendl (Lendava), Vesna Kutnjak (Ljutomer), Karmen Plavec (Ormož), Bračko Karel (Ptuj) in Marija Vodušek (Šmarje pri Jelšah).

Schultes - Becker, I., 1990, Auswirkungen einer "partiell offenen" Grenze auf das Verhalten der Bevoelkerung - das Beispiel der Gemeinden Lichtenberg und Schirnding in Oberfranken. Arbeitsmaterialien zur Raumordnung und Raumplanung. Heft 26. Bayreuth, str. 83-88,96 


\section{GRENZUEBERSCHREITENDE GRUNDBESITZVERMISCHUNG UND BESCHAEFTIGUNG - BEISPIEL DER GEMEINDEN NORDOSTSLOWENIENS AN DER SLOWENISCH-KROATISCHEN GRENZE}

\section{Zusammenfassung}

Aufgrund der Analyse der Grundbesitz- und Beschaeftigungscharakteristik werden einige Elemente der grenzueberschreitenden regionalen Verflechtung der Gemeinden Lendava, Ljutomer, Ormož, Ptuj und Šmarje pri Jelšah bestimmt. Die slowenische geographische Wissenschaft untersuchte im Rahmen der regionalen Forschungen seit den 70-er Jahren ueberwiegend die Grenzgebiete mit Oesterreich, Italien und Ungarn, vor allem die Problematik der ethnischen Minderheiten. Die Verselbstaendigung Sloweniens und die Entstehung der neuen Staatsgrenze mit Kroatien bedeutet fuer sie eine Aufforderung, mit seinen Untersuchungen zur Loesung von Problemen und Konflikten beizutragen.

Unter die Faktoren der regionalen Differenzierung zaehlen vor allem die Abwechslung der Ebene- und Huegellandschaft mit ihrer vielfaeltigen Landwirtschaft, verschiedenartige Stufe der Deagrarisation und Depopulation sowie die historische Entwicklung.

Die Grundbesitzvermischung an der slowenisch-kroatischen Grenze ist gegenseitig, waehrend sich bei der Beschaeftigungsproblematik mit einigen Ausnahmen (Rogatec) nur um die kroatischen Pendler in den slowenischen Grenzzentren handelt

Die Beschaeftigungsstroeme stammen vor allem aus dem Kroatischen Medmurje, aus der Ebene von Varaždin und aus Hrvatsko Zagorje

Im Jahr 1992 gab es in fuenf angefuerten Gemeinden 4690 Eigentuemer aus Kroatien (in der Gemeinde Lendava die Miteigentuemer eingezaehlt) mit ingesamt 1967 ha Land. Davon waren $32 \%$ Aecker, $2 \%$ Obstgaerten, $8 \%$ Weingaerten, $26 \%$ Wiesen, $7 \%$ Weiden, $22 \%$ Waelder und $3 \%$ unfruchtbares Land. Auf einen Eigentuemer fielen 0.34 ha Land ab. Die kroatischen Eigentuemer besassen ihr Land in 186 Katastralgemeinden, in 16 von 5 bis 10 $\%$ und in 4 ueber $10 \%$ Katastralflaeche

Die staerkste Grundbesitzvermischung ist auf dem Gebiet von Medmurje zu finden. Als Beispiel dienten uns die Katastralgemeinden Dolina, Hotiza und Gibina. Intensiv ist auch der Pendelverkehr, denn im Jahr 1992 pendelten taeglich in die Grenzgemeinden Nordostsloweniens mehr als 2500 Personen

Aus der ehemaligen Grenze zwischen Slowenien und Kroatien im Rahmen von Jugoslawien hat sich ein theoretisch besonders anregender Grenztyp entwickelt, den man in den partiell offenen "Brueckentyp" einordnen koente. Es waere wuenschenswert, dass die zwischenstaatlichen Abkommen ueber Doppeleigentum, Kleingrenzverkehr und Beschaeftigung eine intensivere, ungehinderte grenzuebersreitende Verflechtung der Bevoelkerung ermoeglichen, dass sie vor allem aber die Entwicklungstendenz in eine offene "Scharniergrenze" foerdern. 